\title{
FAT ABSORPTION STUDIES IN THE DIAGNOSIS AND TREATMENT OF PANCREATIC FIBROSIS
}

\author{
BY \\ CONSTANCE A. C. ROSS \\ From the Department of Paediatrics and Child Health and the Department of Pharmacology, University of Birmingham
}

(RECEIVED FOR PUBLICATION DECEMBER 10, 1954)

The presence of steatorrhoea in pancreatic fibrosis was formerly the cause of its confusion with coeliac disease. This confusion was dispelled by the studies of Blackfan and Wolbach (1933) and of Andersen (1938) who clearly separated pancreatic fibrosis as a separate entity by showing that in this disease there was atrophy of the secretory tissue of the pancreas and that the steatorrhoea resulted from deficiency in pancreatic lipase. Andersen (1945) claimed that, although analysis of single stools or three-day stool collections generally revealed a great increase of faecal fat in pancreatic fibrosis, this was not always found. In the light of recent work, however (Kamer, Bokkel Huinink and Weyers, 1949), it would appear that fat balance studies are necessary for a reliable assessment of fat absorption.

In the treatment of pancreatic fibrosis Andersen (1949) stressed the importance of maintaining satisfactory nutrition and claimed that the respiratory involvement, which is such a common feature of this disease, might be secondary to impaired absorption of some substance essential for the normal functioning of the bronchi. The value of pancreatin in improving absorption of food substances in pancreatic fibrosis has been studied by various workers. Shohl, May and Shwachman (1943) found that although pancreatin resulted in a reduction of faecal nitrogen there was no significant decrease in faecal fat, whereas Andersen (1945) using a pancreatin preparation of higher lipase content than that employed by Shohl et al. showed that it produced a considerable decrease in faecal fat. May and Lowe (1949), however, have questioned the usefulness of pancreatin in the treatment of this disease.

The object of the present study was to ascertain the magnitude of the fat absorption defect in pancreatic fibrosis by means of fat-balance studies and chylomicrographs, and to compare the findings with those obtained in coeliac disease. From the fat absorption findings in pancreatic fibrosis an attempt was made to estimate the value of pancreatin in treatment and to place dosage on a rational basis.

\section{Materiaks and Methods}

Clinical Material. This comprised 22 children with pancreatic fibrosis, aged from 2 weeks to 5 years, who were studied in the Children's Hospital, Birmingham. The diagnosis was established by the absence or marked reduction in duodenal juice of the pancreatic enzymes, lipase and trypsin, or by necropsy findings. Eighteen children under 5 years of age with coeliac disease were investigated in the hospital during the same period. The diagnosis of coeliac disease was made before treatment with a wheat gluten-free diet by the investigations described by Anderson, Frazer, French, Gerrard, Sammons and Smellie (1952). These investigations were repeated after the children had received this diet for three to six months. The results of the fat-balance studies and chylomicrographs in the children with pancreatic fibrosis have been compared with those in the patients with coeliac disease both before and after treatment with a wheat gluten-free diet.

Pancreatic Enzymes. The enzyme estimations were made on three separate samples of duodenal juice from each intubation, and the average values obtained.

Lipase was measured by the following method: to $5 \mathrm{ml}$. phosphate buffer containing $0 \cdot 5^{\circ}$ bile salts, at $p \mathrm{H} 7 \cdot 8$, in a $50-\mathrm{ml}$. stoppered conical flask was added $1 \mathrm{ml}$. of acid-free olive oil and $0.1 \mathrm{ml}$. of duodenal juice. The mixture was shaken for 30 minutes at $37^{\circ} \mathrm{C}$., acidified, extracted with $20 \mathrm{ml}$. benzene and $10 \mathrm{ml}$. of the upper benzene layer was titrated with $0.05 \mathrm{~N}$ tetramethylammonium hydroxide in alcohol. The titration figure in ml. gave the units of lipase per $0.1 \mathrm{ml}$. duodenal juice (Frazer and Sammons, 1955).

Trypsin was estimated by the method described by Tomarelli, Charney and Harding (1949) using azoalbumin as substrate.

In 20 'normals', that is children who were not suffering from steatorrhoea, the range of lipase in $0.1 \mathrm{ml}$. duodenal juice was 1.2 to 5.5 units (mean 3.2 units) and the range of trypsin in $1 \mathrm{ml}$. duodenal juice was 3.4 to 27 units (mean 13 units). 
Fat Absorption. A fat balance was carried out on each child for a minimum period of five consecutive days, with the exception of eight children with pancreatic fibrosis who were too ill for metabolic studies. For this purpose the patient received a known dietary fat intake, 20 to $50 \mathrm{~g}$. daily according to age. The stools were collected daily, a metabolism bed being used for infants or when the stools were loose. Estimation of the faecal fat was carried out by a modification of the fatty acid method of Kamer et al. (1949). The daily totals of faecal fatty acids were converted to three-day sliding means to minimize sampling errors, and the mean fercentage fat absorption for the period obtained. In normal children, fat absorption is over $90^{\circ}$ of the fat intake (Gerrard, Ross, Astley, French, and Smellie, 1954).

Systemic Hyperlipaemia. This was investigated by means of the chylomicrograph technique described by Frazer and Stewart (1939). A specimen of blood was taken from the fasting child into a capillary tube. A meal containing 5-20 g. fat, depending on age, was then given: the standard meal for the infant consisted of a National dried milk formula: for the older child the fat was contained in milk, butter and eggs. Specimens of capillary blood were taken at hourly intervals after the meal, up to five hours. The specimens of blood were allowed to clot, one end of each tube sealed in a flame, and the tubes then centrifuged for five minutes. A drop of the serum was placed on a microscope slide, covered with a coverslip, and examined under a microscope with dark-ground illumination. The number of bright, mobile particles in a standard field (a square $0.5 \mathrm{~cm}$. $\times 0.5 \mathrm{~cm}$.) were counted, and the average of three fields taken. From these counts, the maximum chylomicron increment, i.e. the greatest increase in fat particles above the fasting value, was obtained for each patient. By this method the maximum increment in each of a series of 18 "normal' children under 5 years of age was always over 150 particles.

Pancreatin. The pancreatin used in the present study was obtained from one firm only (Paines and Byrne, Ltd.). Initially it was used both as powder and as granules with a coating to prevent destruction of the enzyme activity by the acid gastric juice: it was then our custom to give powder to infants receiving a milk formula and granules to older children. We found, however, that granules gave very irregular fat absorption figures, probably due to the differing solubility of the coating, and so subsequently we gave the powder to our older children also. Both "single" strength and 'triple' strength pancreatin were used. We found that $0.05 \mathrm{~g}$. of 'single" strength powder contained 5.7 units of lipase and 14 units of trypsin, a lipase to trypsin ratio of $1: 2 \cdot 5$. As the mean figures for the trypsin and lipase content of $1 \mathrm{ml}$. duodenal juice from the "normal' children were 32 units and 13 units respectively, this gave a lipase to trypsin ratio of $1: 0 \cdot 4$. It is thus evident that pancreatin powder is relatively low in lipase compared with normal duodenal juice. In terms of volume of normal duodenal juice, $1 \mathrm{~g}$. of 'single' strength powder had lipase activity approximately equivalent to $3.5 \mathrm{ml}$. and trypsin activity approximately equivalent to $21.5 \mathrm{ml}$.

The pancreatin was administered in cold or lukewarm milk (temperature below $37^{\circ} \mathrm{C}$.). For infants receiving a milk formula the powder was mixed with the feed; for older children it was mixed with a little cold milk and given in the middle of the meal. Our routine was to give the child a small dose of pancreatin, e.g. $0.5 \mathrm{~g}$. 'single' strength per feed, and after three days a fat balance was carried out, and the mean fat absorption on that dosage was obtained. The dose was then increased by $0.5 \mathrm{~g}$. or by $1 \mathrm{~g}$. until the mean fat absorption showed no further increase. 'Triple' was substituted for 'single' strength when the dosage of the latter reached $2 \mathrm{~g}$.

\section{Results}

Pancreatic Enzymes. Estimation of the lipase and trypsin content of duodenal juice was carried out in 17 of the children with pancreatic fibrosis. From Table 1 it will be seen that trypsin was completely absent in all but two (Cases 4 and 14), aged 10 weeks and 2 years respectively. The enzyme estimations were subsequently repeated when these two children were 11 months and 3 years old respectively. Pancreatic trypsin was then completely absent in both, which would suggest that in these two children atrophy of the secretory tissue of the pancreas had been progressive. Small amounts of lipase were detected in seven children, five of whom had no trypsin. Although this might indicate that complete suppression of pancreatic lipase occurs at a later age than that of trypsin, it is possible that the small amounts of lipase obtained might have been extrapancreatic in origin and might depend upon the level of duodenal sampling.

The range of these enzymes in the duodenal juice of the children with coeliac disease was lipase $2 \cdot 6$ to 5 units, trypsin 6 to 46 units; i.e.. both enzymes were within the normal range.

Fat Absorption Studies in Pancreatic Fibrosis and Coeliac Disease. The mean percentage fat absorption in each of the 14 children with pancreatic fibrosis who had a fat balance before pancreatin therapy is shown in Table 1 , from which it may be seen that 11 had figures below $60 \%$. As the three patients with pancreatic fibrosis whose fat absorption figures were over $60 \%$ were all under 1 year of age, it seemed possible that of patients with this disease infants who receive a predominance of milk in their diet might have greater fat absorption figures than older children receiving a mixed diet. In Table 2 and Fig. 1, where we have compared the fat balance findings in pancreatic fibrosis and coeliac disease, we have divided the children in each group 
TABLE 1

PANCREATIC ENZYMES AND FAT ABSORPTION IN PANCREATIC FIBROSIS

\begin{tabular}{|c|c|c|c|c|}
\hline \multirow[b]{2}{*}{ Patient } & \multirow[b]{2}{*}{ Age } & \multicolumn{2}{|c|}{ Duodenal Enzymes } & \multirow{2}{*}{$\begin{array}{l}\text { Fat Absorption ( } \% \text { ) } \\
\text { (Mean of } 5 \text { to 10-Day } \\
\text { Balance) }\end{array}$} \\
\hline & & $\begin{array}{l}\text { Lipase } \\
\text { (units } / 0 \cdot 1 \mathrm{ml} . \text { ) }\end{array}$ & $\begin{array}{c}\text { Trypsin } \\
\text { (units } / 1 \mathrm{ml} \text {.) }\end{array}$ & \\
\hline 1 & \multirow{18}{*}{ 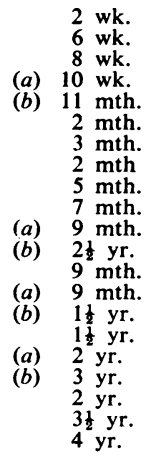 } & \multirow{18}{*}{$\begin{array}{l}0 \cdot 3 \\
0 \\
0 \\
0 \cdot 3 \\
0 \\
0 \\
0 \\
0 \\
0 \\
0 \\
0 \cdot 1 \\
0 \cdot 1 \\
0 \\
0 \\
\text { Not done } \\
0 \\
0 \cdot 3 \\
0 \cdot 1 \\
0 \\
0 \cdot 1 \\
0\end{array}$} & 0 & \multirow{18}{*}{$\begin{array}{l}\text { Not done } \\
, ", " \\
, ", \\
79 \cdot 5 " \\
\text { Not done } \\
40 \\
48 \\
72 \\
81 \\
\text { Not done } \\
39 \\
58 \\
54 \\
57 \\
54 \\
\text { Not done } \\
26 \\
52 \\
52 \\
52\end{array}$} \\
\hline 2 & & & 0 & \\
\hline $\begin{array}{l}3 \\
4\end{array}$ & & & & \\
\hline & & & 0 & \\
\hline 5 & & & 0 & \\
\hline 6 & & & 0 & \\
\hline 7 & & & 0 & \\
\hline 8 & & & 0 & \\
\hline 9 & & & 0 & \\
\hline 10 & & & 0 & \\
\hline 11 & & & 0 & \\
\hline 12 & & & 0 & \\
\hline & & & Not done & \\
\hline $\begin{array}{l}13 \\
14\end{array}$ & & & $\begin{array}{l}0 \\
7.8\end{array}$ & \\
\hline 14 & & & 0 & \\
\hline 15 & & & 0 & \\
\hline 16 & & & 0 & \\
\hline 17 & & & 0 & \\
\hline
\end{tabular}

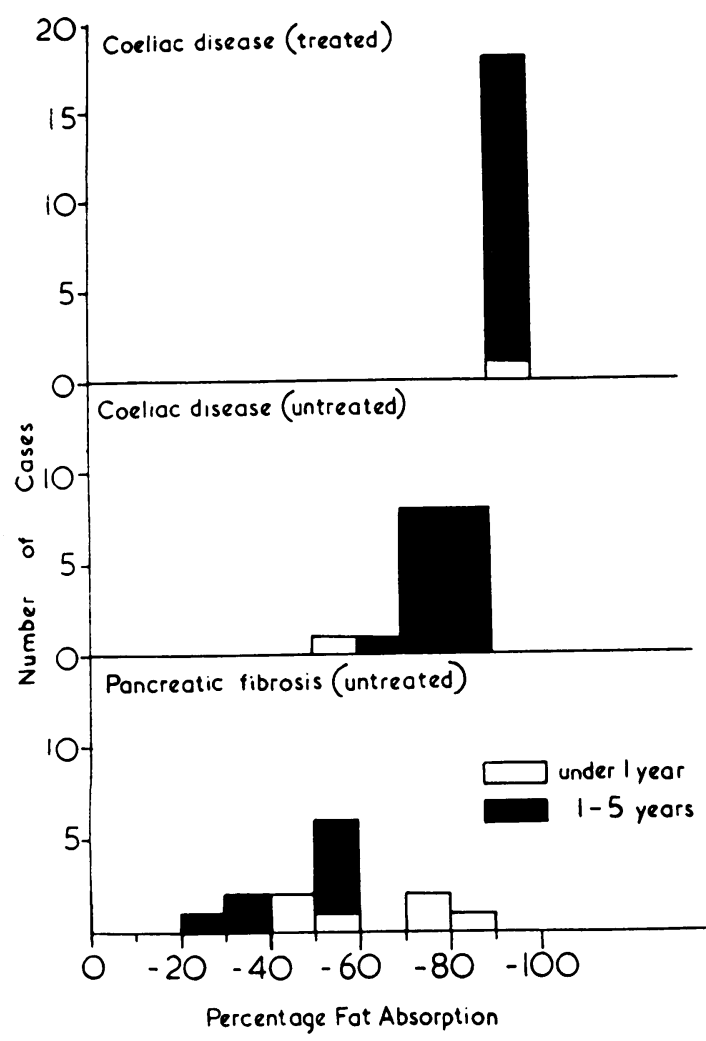

Fig. 1.-Fat absorption in pancreatic fibrosis and coeliac disease.

into those under and those over 1 year of age. Before treatment with a wheat gluten-free diet only one of the 18 children with coeliac disease had a fat absorption below $60 \%$. She was 11 months old, the only child in this group who was under 1 year of age; the marked steatorrhoea in her case may have resulted in an unusually early diagnosis of coeliac disease. After treatment with a wheat gluten-free diet the fat absorption figures in all 18 children had risen above $90 \%$ (mean $92 \cdot 5$ ). It would thus appear that in children over 1 year of age steatorrhoea is more marked in pancreatic fibrosis than in coeliac disease but that in children under 1 year of age, with pancreatic fibrosis, fat absorption may be relatively high.

Systemic Hyperlipaemia. The maximum chylomicrograph increments obtained after a standard fat meal in the three groups are shown in Table 3. Of the 22 children with pancreatic fibrosis, 21 had a maximum chylomicron increment under 50 and in 18 the maximum increment was below 25 . On the other hand, of the 18 children with untreated coeliac disease, only three had a maximum increment below 50. That the chylomicograph is frequently depressed, however, in untreated coeliac disease (as previously shown by Anderson et al., 1952) is evident from the finding that only four of these patients had a maximum increment over $150 \mathrm{com}$ pared with 10 of these children after treatment. It was interesting that the only case of pancreatic fibrosis with a maximum increment over 50 was an infant 10 weeks of age in whom duodenal intubation had shown the presence of trypsin and lipase, although both greatly reduced below normal values. On reinvestigation when 11 months old he then had complete absence of duodenal enzymes and a flat chylomicrograph. It thus appears that although a flat chylomicrograph (maximum increment below 50) 
TABLE 2

FAT ABSORPTION IN PANCREATIC FIBROSIS AND COELIAC DISEASE

\begin{tabular}{|c|c|c|c|c|c|c|c|c|c|c|c|}
\hline & & & \multirow{2}{*}{$\begin{array}{c}\text { Total } \\
\text { Patients }\end{array}$} & \multirow[b]{2}{*}{$20-30$} & \multirow[b]{2}{*}{$31-40$} & \multirow[b]{2}{*}{$41-50$} & \multirow{2}{*}{$\frac{\text { Percentage }}{51-60}$} & \multicolumn{2}{|c|}{ Fat Absorption } & \multirow[b]{2}{*}{$81-90$} & \multirow[b]{2}{*}{$91-100$} \\
\hline & & & & & & & & $61-70$ & $71-80$ & & \\
\hline $\begin{array}{c}\text { Pancreatic Fibrosis } \\
\text { Under } 1 \text { yr. } \\
1-5 \text { yr. } \ldots\end{array}$ & $\ddot{ }$ & . & $\begin{array}{l}6 \\
8\end{array}$ & $\overline{1}$ & $\overline{2}$ & $\begin{array}{l}2 \\
-\end{array}$ & $\begin{array}{l}1 \\
5\end{array}$ & - & $\frac{2}{-}$ & 1 & $\overline{-}$ \\
\hline Totals & $\ldots$ & .. & 14 & 1 & 2 & 2 & 6 & - & 2 & 1 & - \\
\hline $\begin{array}{c}\text { Coeliac Disease (un } \\
\text { Under } 1 \text { yr. } \\
1-5 \text { yr. } \quad \cdots\end{array}$ & $\begin{array}{l}\text { tree } \\
\cdots \\
\cdots\end{array}$ & $\begin{array}{l}\text { d) } \\
\cdots\end{array}$ & 17 & - & - & - & $\frac{1}{-}$ & $\overline{1}$ & $\overline{8}$ & $\overline{8}$ & $\overrightarrow{-}$ \\
\hline Totals & $\cdots$ & $\cdots$ & 18 & - & - & - & 1 & 1 & 8 & 8 & - \\
\hline $\begin{array}{c}\text { Coeliac Disease (tre } \\
\text { Under } 1 \text { yr. } \\
1-5 \text { yr. } \quad \cdots\end{array}$ & $\begin{array}{l}\text { eate } \\
\cdots \\
\cdots\end{array}$ & $\cdots$ & $\begin{array}{r}1 \\
17\end{array}$ & $\overline{-}$ & $\overline{-}$ & $\overline{-}$ & - & - & - & $\overline{-}$ & 17 \\
\hline Totals & $\ldots$ & $\ldots$ & 18 & - & - & - & - & - & - & - & 18 \\
\hline
\end{tabular}

TABLE 3

CHYLOMICROGRAPHS IN PANCREATIC FIBROSIS AND COELIAC DISEASE

\begin{tabular}{|c|c|c|c|c|c|c|c|c|c|}
\hline & & \multirow{2}{*}{$\begin{array}{l}\text { Total } \\
\text { Cases }\end{array}$} & \multicolumn{7}{|c|}{ Number of Cases with Maximum Increment } \\
\hline & & & $0-25$ & $26-50$ & $51-75$ & $76-100$ & $101-125$ & $126-150$ & $150+$ \\
\hline Pancreatic fibrosis & $\cdots$ & 22 & 18 & 3 & - & - & - & - & 1 \\
\hline $\begin{array}{l}\text { Coeliac disease } \\
\text { (a) untreated }\end{array}$ & $\cdots$ & 18 & 1 & 2 & 6 & 3 & - & 2 & 4 \\
\hline $\begin{array}{r}\text { Coeliac disease } \\
\text { (b) treated } \ldots\end{array}$ & $\cdots$ & 18 & - & - & 1 & 2 & 3 & 2 & 10 \\
\hline
\end{tabular}

TABLE 4

EFFECT OF PANCREATIN ON FAT ABSORPTION

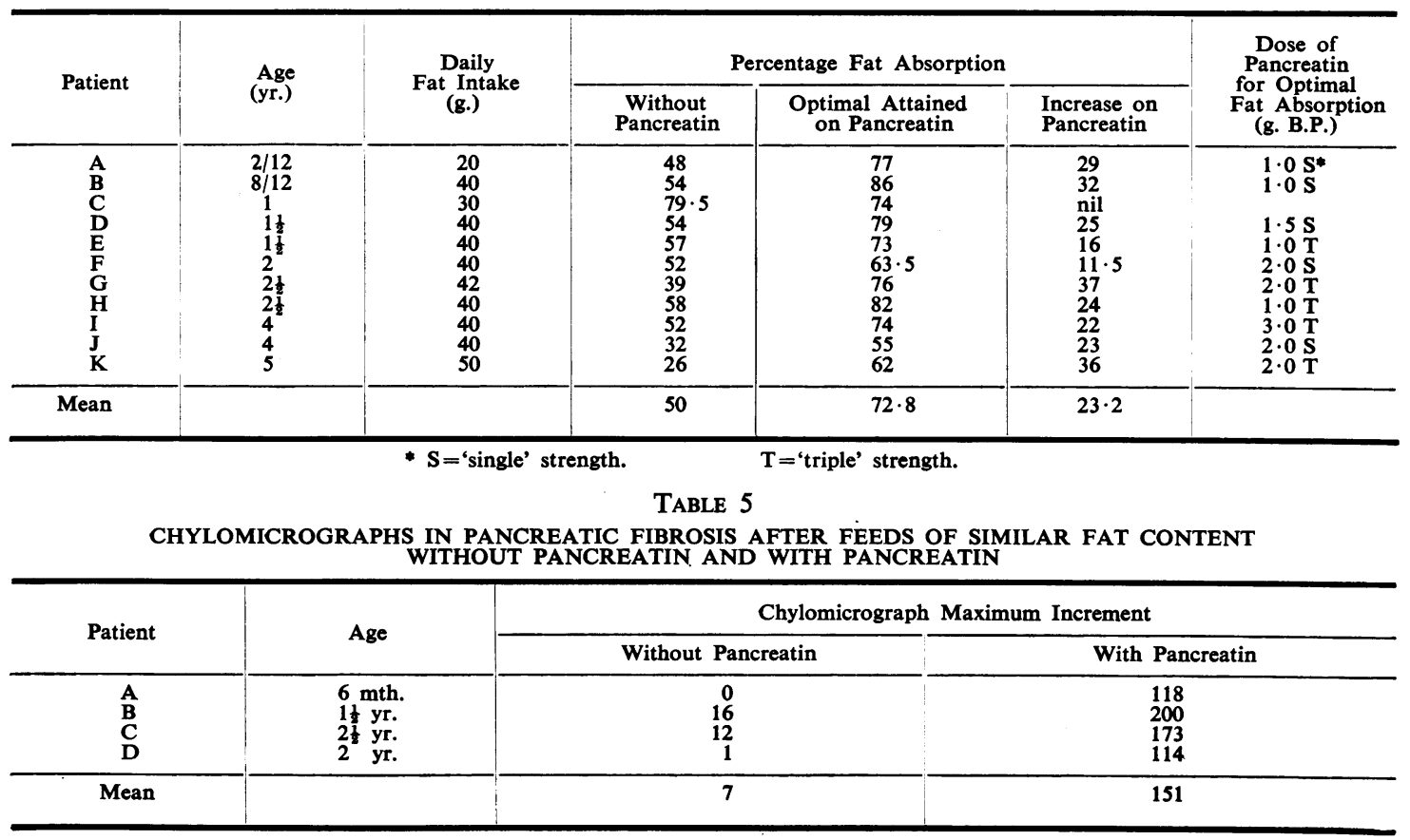


is a very useful test of pancreatic fibrosis, yet the chylomicrograph may be normal when the pancreatic pathological process has not yet resulted in complete absence of lipase.

Effect of Pancreatin on Fat Absorption by FatBalance Studies. From Table 4 it will be seen that pancreatin resulted in considerable improvement in fat absorption in 10 out of 11 children with pancreatic fibrosis. The percentage increase in fat absorption ranged from 11 to 29 with a mean of $23 \cdot 2^{\circ}{ }_{0}$. It was found that for each patient a certain dosage of pancreatin produced optimal fat absorption, and that an increase above this dosage produced no further improvement and sometimes even deterioration. The amount per feed required for optimal fat absorption ranged from 1 g. B.P. 'single" to 3 g. B.P. 'triple". This dosage bore no obvious correlation to the daily fat intake or to the percentage fat absorption before pancreatin was given. It will be noted, however, that the child with the highest fat absorption before treatment was the one who showed no improvement with pancreatin. Although the number of cases in this study was small, a rough correlation was found between the optimal dosage of pancreatin and the age of the child.

Systemic Hyperlipaemia after Pancreatin. The maximum chylomicron increments obtained in four children with pancreatic fibrosis after feeds of similar fat content $(a)$ without pancreatin and (b) with pancreatin are shown in Table 5. In each case the chylomicrograph obtained after the feed with pancreatin was considerably higher than that without pancreatin.

\section{Discussion}

The differential diagnosis between pancreatic fibrosis and coeliac disease is frequently difficult. Although absence or marked reduction of pancreatic enzymes in duodenal juice is undoubtedly the most reliable diagnostic test of pancreatic fibrosis, duodenal intubation is not always possible either because the child may be too ill or because of lack of radiological screening facilities. A low content of proteolytic activity in the stool is sometimes used as a diagnostic test of pancreatic insufficiency, but Sammons, Ross and Wood (1954) have shown that this is an unreliable index of pancreatic function. Our present studies have demonstrated that both fat-balance studies and chylomicrographs may be of considerable value in the differential diagnosis of pancreatic fibrosis and coeliac disease. Fat-balance studies revealed a clear-cut difference in the fat absorption figures between the two conditions in children over 1 year of age; in children under 1 year of age receiving a predominance of milk in their diet this difference was not observed. A maximum chylomicron increment below 50 was strongly in favour of pancreatic fibrosis; this finding is in keeping with those reported by Elghammer, Reichert and Philipsborn (1950) and Payne (1952). Moreover, we found that the chylomicrograph was generally more useful than a fat balance in the differential diagnosis as it is simple to carry out and is less time consuming and troublesome for patient, laboratory staff and nursing staff. Again, since pancreatic fibrosis is a hereditary disease, it is sometimes desirable to exclude its presence in siblings and for this purpose the chylomicrograph is a useful outpatient test.

We have demonstrated the value of pancreatin in improving fat absorption as evidenced both by fat-balance studies and by chylomicrographs. For each child there was a certain dosage of pancreatin which produced an optimal increase in percentage fat absorption; this was always accompanied by a progressive increase in weight. Increase in this dosage not only failed to produce further improvement in fat absorption but frequently resulted in deterioration. The reason for this is unknown but it may be that for optimal fat absorption lipolysis must be such as to produce a certain proportion of neutral fats and fatty acids. It was of interest that, although there was considerable improvement in fat absorption with pancreatin, in all the children the highest figures were considerably below normal. Several hypotheses may be advanced to explain this. It may be that pancreatin even when given with the meal achieves less intimate mixture with the food than does the coordinated flow of pancreatic juice. Again, the lipase/trypsin ratio may be of importance: in pancreatic extracts this ratio is much lower than that found in duodenal juice. It also seems possible that besides lipase some other factor which is necessary for normal fat absorption may be absent or depressed in the child with pancreatic fibrosis.

It is obvious that for assessment of pancreatic therapy fat-balance studies cannot be carried out on all children with pancreatic fibrosis. Again, the increase obtained in the chylomicron increment after a standard fat meal with pancreatin is not a satisfactory index of the dosage required, as we found that the optimal dosage for any child as assessed by fat-balance studies did not always correspond to the dosage which gave the highest increase in chylomicron increment. Although the number of cases studied in the present series was 
small, a rough correlation was however obtained between dosage of pancreatin required for optimal fat absorption and the age of the child. For the pancreatin preparation used in the present study the approximate dosage required in relation to age was as follows: under 1 year, 1 g. B.P. "single'; 1-2 years, 2 g. B.P. 'single'-1 g. B.P. 'triple' : 2-5 years, 1 g. B.P. 'triple'-3 g. B.P. 'triple'. Since these studies were done we have found that pancreatin U.S.P. is considerably more potent, weight for weight, than pancreatin B.P. $(0.5$ g. U.S.P. 'single' strength powder contained 15 units lipase and 30 units trypsin), although the highest fat absorption attained in any one child with either type was approximately the same. In children over 2 years of age, where it is sometimes desirable to reduce the bulk of the powder given with each meal in order to disguise its taste, U.S.P. pancreatin may be preferable to B.P.

At the time of the present report it was not possible to deduce from our studies if pancreatin therapy had had any influence on the prevention or amelioration of respiratory involvement, for not only had the follow-up period been too short for this purpose but there were insufficient children in the series to analyse in separate age groups. It was of interest, however, that of the six infants under 1 year of age who had fat-balance studies before being given pancreatin, three had fat absorption figures over $60 \%$, and two of these died of acute respiratory infections before the age of 1 year, whereas of the three babies with a low fat absorption (below $60 \%$ ), one died. These findings do not support the idea that those with a gross defect in fat absorption are most liable to pulmonary infection; this aspect of the problem, however, requires further study.

\section{Summary}

The fat absorption defect was investigated by means of fat-balance studies and chylomicrographs in a series of 22 children under 5 years of age who were suffering from pancreatic fibrosis, and the findings compared with those found in a series of 18 children under 5 years of age with coeliac disease.

Fat-balance studies showed that in the children over 1 year of age the fat absorption percentages in those with pancreatic fibrosis, before pancreatin therapy, were all under 60 , whereas in the children with coeliac disease the figures were over $60 \%$ even when the condition was active. In the children under 1 year of age receiving a predominance of milk in their diets, this difference in fat absorption between pancreatic fibrosis and coeliac disease was not observed.

The chylomicrograph was a very useful test in differential diagnosis: a maximum chylomicron increment of under 50 particles was obtained in 21 out of 22 children with pancreatic fibrosis but in only three out of 18 children with active coeliac disease.

The administration of pancreatin with feeds resulted in considerable improvement in fat absorption in 10 out of 11 children with pancreatic fibrosis, the mean increase in fat absorption being $23.2^{\circ}$ o. It was found that for each patient there was a certain dosage of pancreatin which gave optimal fat absorption as assessed by fat-balance studies, and that this dosage bore a rough correlation to the age of the patient.

I wish to thank the consultant staff of the Children's Hospital, Birmingham, for permission to study their patients, and Sisters N. Howells and J. Woodward as well as their nursing staff for invaluable help with the metabolic studies. I am indebted to Dr. C. M. Anderson for the initial work in the children with coeliac disease. I am grateful to Professor A. C. Frazer, Professor J. M. Smellie, Dr. J. M. French and Dr. H. G. Sammons for helpful advice and criticism, to Dr. R. Astley for radiological assistance with duodenal intubations, and to Miss M. Cutler for technical assistance. This study was made with the help of a grant from the United Birmingham Hospitals Research Fund.

\section{REFERENCES}

Andersen. D. H. (1938). Amer. J. Dis. Child., 56. 344.

(1945). Ibid., 69, 221.

- (1949). Pediatrics, 3. 406.

Anderson, C. M.. Frazer, A. C.. French, J. M., Gerrard. J. W., Sammons, H. G. and Smellie, J. M. (1952). Lancet, 1. 836. Blackfan. K. D. and Wolbach, S. B. (1933). J. Pediat.. 3. 679.

Elghammer, W. R., Reichert, J. M. and Philipsborn, H. F. (1950). Pediatrics, 5, 621.

Frazer, A. C. and Stewart, H. C. (1939). J. Physiol., Lond., 95. 21P. $23 P$.

- and Sammons, H. G. (1955). In the press.

Gerrard, J. W., Ross, C. A. V., Astley, R., French. J. M. and Smellie, J. M. (1954). Quart. J. Med. In the press.

Kamer, J. H. van de, Bokkel Huinink. H. ten and Weyers, H. A. (1949). J. biol. Chem., 177. 347.

May, C. D. and Lowe, C. U. (1949). J. Pediat., 34. 663.

Payne, W. W. (1952). Great Ormond Str. J., 2 (no. 3), p. 23.

Sammons, H. G., Ross, C. A. C. and Wood, W. A. (1954). In the

Shohl, A. T., May, C. D. and Shwachman, H. (1943). J. Pediat., 23, 267.

Tomarelli. R. M., Charney, J. and Harding, M. L. (1949). J. Lab. clin. Med., 34, 428. 